\title{
Competição entre Soja Resistente ao Glyphosate e Plantas Daninhas em Solo Compactado ${ }^{1}$
}

\author{
Competition Between Glyphosate Resistant Soybean and Weeds in Compacted Soil
}

SANTOS, J.B. ${ }^{2}$, LÁZARI, T.M. ${ }^{3}$, CAMELO, G.N. ${ }^{3}$, OLIVEIRA, T.A. ${ }^{4}$ e FIGUEIREDO, J.L.A. ${ }^{2}$

\begin{abstract}
RESUMO - Objetivou-se com este trabalho avaliar a competição entre a soja (var. BRS 243 RR) e as plantas daninhas Bidens pilosa e Brachiaria brizantha, em diferentes niveis de compactação do solo. Para isso, foram confeccionadas colunas de PVC (10 cm de diâmetro) com três anéis: superior (com $5 \mathrm{~cm}$ de altura e densidade de $1,2 \mathrm{~kg} \mathrm{dm}^{-3}$ ), intermediário (com $10 \mathrm{~cm}$ de altura e densidade variando entre 1,0 e 1,6 $\mathrm{kg} \mathrm{dm}^{-3}$, conforme tratamento) e inferior (com $10 \mathrm{~cm}$ de altura e densidade de $1,2 \mathrm{~kg} \mathrm{dm}^{-3}$ ). Sobre as colunas foram realizados cinco cultivos: soja, $B$. pilosa, $B$. brizantha, soja e $B$. pilosa e soja e B. brizantha, em esquema fatorial com as densidades, perfazendo um total de 20 tratamentos. Aos 30 dias após emergência da soja, foram avaliadas a altura, a massa seca de folhas, de caule e de raizes (em cada anel, separadamente), a área foliar e a área foliar específica. Observou-se que $B$. brizantha foi mais competitiva que $B$. pilosa; contudo, esta última possui maior capacidade de exploração radicular em solos com maior nivel de compactação, indicando maior adaptabilidade a condições como déficit hídrico e escassez de nutrientes. Considerando a capacidade competitiva da soja sobre as plantas daninhas, maiores niveis de compactação favorecem a cultura, em relação a $B$. pilosa.
\end{abstract}

Palavras-chave: Bidens pilosa, Brachiaria brizantha, densidade do solo, Glycine max.

\begin{abstract}
This work aimed to evaluate competition between soybean (BRS $243 R R)$ and the weeds Bidens pilosa and Brachiaria brizantha, in soil with simulated compactation. Thus columns of PVC tubes $(10 \mathrm{~cm}$ of diameter) were made with three rings (superior $(5 \mathrm{~cm}$ high and $1.2 \mathrm{~kg} \mathrm{dm} \mathrm{m}^{-3}$ density); intermediate $\left(10 \mathrm{~cm}\right.$ high and around 1.0 and $1.6 \mathrm{~kg} \mathrm{dm}^{-3}$ density) and

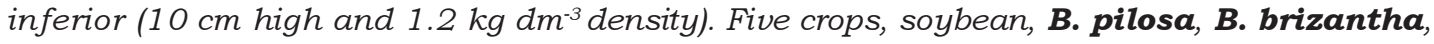
soybean and $\boldsymbol{B}$. pilosa, and soybean and $\boldsymbol{B}$. brizantha, were cultivated on the columns in a factorial scheme with the densities, totaling 20 treatments. At 30 days after soybean emergence, height leaf, stem and root dry matter, leaf area and specific leaf area were evaluated. B. brizantha was more competitive than $\boldsymbol{B}$. pilosa, but the latter had higher radicular exploration capacity in soil with higher compactation level, indicating higher suitability under hydric deficit and nutrient scarcity conditions. Considering soybean competitive capacity over weeds, higher compactation levels favor the culture in relation to $\boldsymbol{B}$. pilosa.
\end{abstract}

Keywords: Bidens pilosa, Brachiaria brizantha, soil density, Glycine max.

\section{INTRODUÇÃO}

As decisões de controle de plantas daninhas em lavouras de soja geneticamente modificadas, resistentes ao glyphosate, têm base nas espécies e intensidade presentes, bem como na redução que causam no rendimento da cultura. As perdas no rendimento da soja causadas pela interferência das plantas daninhas são variáveis com as condições edafoclimáticas e de manejo da lavoura, podendo, inclusive, comprometer toda a produção (Silva

1 Recebido para publicação em 26.6.2007 e na forma revisada em 27.2.2008

2 Professor de Agronomia Univale, Rua Israel Pinheiro, 2000 - Campus II/UNIVALE, 35020-220, Governador Valadares - MG, $<$ jbarbosa@univale.br>; ${ }^{3}$ Acadêmicos curso de Agronomia da UNIVALE; ${ }^{4}$ Acadêmica do curso de Ciências Biológicas da UNIVALE. 
et al., 2007). Nesse sentido, a adoção de medidas como a implantação do sistema de plantio direto pelos agricultores tem contribuído para o sucesso no controle de algumas espécies de plantas daninhas.

No sistema de plantio direto, a ausência ou revolvimento mínimo do solo favorece a manutenção de teores de água mais elevados em virtude da permanência na superficie dos resíduos culturais, além da reestruturação do solo a partir do desenvolvimento radicular ao longo dos ciclos de cultivo. Entretanto, com o tráfego sistemático de máquinas, principalmente na fase inicial de adoção desse sistema, poderá ocorrer compactação na camada superficial do solo (Tormena \& Roloff, 1996), sobretudo naquele com elevado teor de argila, conforme o tamanho e formato de partículas. A compactação promovida pelas máquinas pode ser superficial, dada a pressão de ar nos pneus, ou em camadas mais internas (subsuperficial), provocada pelo peso dos tratores e colhedoras (Hakansson \& Voorhees, 1996). Tem sido observado, na maioria das vezes, que a compactação mais prejudicial ocorre nos primeiros centímetros do solo e raramente excede os $50 \mathrm{~cm}$ de profundidade (Daniel \& Maretti, 1990).

A compactação do solo pode ser entendida como o processo em que a porosidade e a permeabilidade são reduzidas, com aumento da resistência à penetração, promovendo mudanças na estrutura do solo (Soane \& van Ouwerkerk, 1994) e podendo alterar suas características. As raízes diminuem de diâmetro para penetrar pequenos poros, pois a resistência mecânica do solo estimula a proliferação das raízes laterais, as quais são mais finas (Russel \& Goss, 1974). Contudo, com a resistência mecânica do solo, há aumento do diâmetro das raízes na camada compactada em função das modificações morfológicas e fisiológicas, específicas a cada espécie ou cultivar (Materechera et al., 1992).

Os resultados referentes aos estudos da sensibilidade de culturas aos niveis de compactação de solos sob o sistema de plantio convencional e direto são abundantes (Tormeta \& Roloff, 1996; Guimarães et al., 2002; Foloni et al., 2003; Secco et al., 2004). No entanto, ainda não foi caracterizado o efeito da compactação do solo sobre a competição de determi- nadas espécies de plantas daninhas com as culturas, particularmente com a soja transgênica, que tem preferência pelos agricultores para cultivo. A utilização de glyphosate nessa cultura diminuiu o custo do controle de plantas daninhas (Monquero, 2005), porém está causando seleção de espécies tolerantes e resistentes a esse herbicida (Vargas et al., 2005; Ferreira et al., 2006).

Espécies como picão-preto (Bidens pilosa) e braquiarão (Brachiaria brizantha) são facilmente encontradas em competição com as culturas, sendo de dificil manejo com a utilização única de herbicidas (Winkler et al., 2002; Timossi et al., 2006; Vidal et al., 2006). A avaliação da agressividade dessas espécies com plantas de soja em solos compactados pode ser útil no estabelecimento de estratégias de controle alternativas à aplicação de herbicidas.

Objetivou-se com este trabalho avaliar a competição entre a soja (var. BRS 243 RR) e as plantas daninhas Bidens pilosa e Brachiaria brizantha, em diferentes niveis de compactação do solo.

\section{MATERIAL E MÉTODOS}

O experimento foi conduzido em casa de vegetação, pertencente ao Núcleo de Pesquisa em Agronomia - NUPEAGRO da Universidade Vale do Rio Doce - UNIVALE. O solo utilizado para a pesquisa é argilo-siltoso, com as características químicas apresentadas na Tabela 1.

Foram confeccionadas colunas cilindricas de material tipo PVC de $100 \mathrm{~mm}$ de diâmetro, constituídas por três anéis com alturas de 5, 10 e $10 \mathrm{~cm}$, respectivamente superior, intermediário e inferior.

$\mathrm{O}$ experimento foi montado em esquema fatorial $5 \times 4$, sendo os tratamentos compostos pela combinação de cinco cultivos [Glycine max var. BRS 243 RR (soja transgênica), Bidens pilosa (picão-preto), Brachiaria brizantha (braquiária), soja + picão-preto e soja + braquiária)] e quatro níveis de compactação do solo no anel intermediário $\left(1,0 ; 1,2 ; 1,4 ; \mathrm{e} 1,6 \mathrm{~kg} \mathrm{dm}^{-3}\right)$. O delineamento experimental foi o de blocos casualizados, com quatro repetições.

O solo, depois de seco ao ar e peneirado com malha de $4 \mathrm{~mm}$, foi depositado, na densidade de $1,2 \mathrm{~kg} \mathrm{dm}^{-3}$, em todos os anéis 
Tabela 1 - Características físico-químicas do substrato utilizado no experimento, após correção e adubação. Governador ValadaresMG, 2007

\begin{tabular}{|c|c|c|c|c|c|c|c|c|c|c|}
\hline \multicolumn{11}{|c|}{ Análise granulométrica $\left(\mathrm{dag} \mathrm{kg}^{-1}\right)$} \\
\hline Argila & \multicolumn{2}{|c|}{ Silte } & \multicolumn{2}{|c|}{ Areia fina } & \multicolumn{3}{|c|}{ Areia grossa } & \multicolumn{3}{|c|}{ Classe textural } \\
\hline 34,5 & \multicolumn{2}{|c|}{49,32} & \multicolumn{2}{|c|}{6,77} & \multicolumn{3}{|c|}{9,42} & \multicolumn{3}{|c|}{ Argilo-siltosa } \\
\hline \multicolumn{11}{|c|}{ Análise Química } \\
\hline $\mathrm{pH}$ & $\mathrm{P}$ & $\mathrm{K}^{+}$ & $\mathrm{H}+\mathrm{Al}$ & $\mathrm{Al}^{3+}$ & $\mathrm{Ca}^{2+}$ & $\mathrm{Mg}^{2+}$ & $\mathrm{T}$ & \multicolumn{2}{|c|}{$\mathrm{Vm}$} & $\mathrm{MO}$ \\
\hline $\mathrm{H}_{2} \mathrm{O}$ & \multicolumn{2}{|c|}{$--\mathrm{mg} \mathrm{dm}^{-3}--$} & \multicolumn{5}{|c|}{-------------------------- $\mathrm{cmol}_{\mathrm{c}} \mathrm{dm}^{-3}$------------------------- } & +--- & 0 ----- & -- dag $\mathrm{kg}^{-1}$-- \\
\hline 6,2 & 8,1 & 236,5 & 1,70 & 0,12 & 2,91 & 0,80 & 6,26 & 72,8 & 2,56 & 1,52 \\
\hline
\end{tabular}

Análises realizadas nos Laboratórios de Análises Físicas e Químicas de Solo do Núcleo de Pesquisa em Agronomia - NUPEAGRO da UNIVALE.

inferiores para todos os tratamentos. Em seguida, o anel intermediário foi vedado com parafina e fita adesiva e preenchido com solo nas densidades de 1,0 e $1,2 \mathrm{~kg} \mathrm{dm}^{-3}$. Para produzir as densidades de 1,4 e 1,6 $\mathrm{kg} \mathrm{dm}^{-3}$, utilizou-se uma prensa hidráulica sobre o solo nos anéis predefinidos separadamente, sendo, após, vedados aos anéis inferiores. Em seguida, os anéis superiores de $5 \mathrm{~cm}$ foram vedados sobre aquele que estavam com os tratamentos do fator densidade e receberam solo na densidade de $1,2 \mathrm{~kg} \mathrm{dm}^{3}$.

Em cada coluna foram depositadas três sementes da soja e/ou dez sementes das plantas daninhas, conforme tratamento. Após a emergência das plântulas, realizou-se desbaste, deixando-se uma plântula por coluna. A umidade no solo foi mantida por meio de irrigações diárias a, aproximadamente, $75 \%$ da capacidade de campo. Os dados referentes às temperaturas máximas e mínimas foram monitorados diariamente, e todos os demais tratos fitossanitários, incluindo controle de doenças e pragas, foram realizados conforme necessidade.

Após 30 dias da emergência da soja, as plantas da cultura e das espécies daninhas foram cortadas rente ao solo, sendo determinadas a altura $(\mathrm{cm})$, massa seca de folhas e caules (g), área foliar $\left(\mathrm{cm}^{2}\right)$ e massa seca das raízes em cada anel. Para determinação da massa seca de cada parte da planta, o material foi seco em estufa a $75{ }^{\circ} \mathrm{C}$ por 72 horas, sendo posteriormente pesado em balança de precisão. Para determinação da área foliar, utilizou-se o recurso fotográfico, sendo as imagens de todas as folhas de cada planta, após destacadas, capturadas em programa de imagens em escala predefinida e analisadas pelo programa Image Pro-Plus.

Após tabulação dos dados primários, estabeleceu-se a área foliar específica, por meio da relação entre área total das folhas por plantas e massa seca de folhas.

Os dados foram submetidos à analise de variância, sendo as médias, quando significativas, comparadas pelo teste de Tukey, para as médias relacionadas à soja, ou pelo teste $\mathrm{F}$, para duas médias, no caso das plantas daninhas, ambos a 5\% de probabilidade. Confeccionaram-se também curvas de regressão para a relação densidade do solo e variáveis avaliadas, para as médias significativas testadas em " $t$ " a $5 \%$ de probabilidade.

\section{RESULTADOS E DISCUSSÃO}

Entre as densidades, observou-se efeito significativo $(\mathrm{P}<5 \%)$ para estimativa de regressões somente para massa seca de raízes e área foliar da soja e área foliar, no caso das plantas daninhas.

Houve diminuição no crescimento das plantas de soja em função da competição com as espécies infestantes, sendo esse efeito mais pronunciado com o aumento da compactação.

Considerando os cultivos dentro de cada densidade, a altura e o número de folíolos por planta não foram afetados quando a soja foi cultivada isolada, independentemente do grau de compactação no solo (Tabela 2).

De maneira geral, $B$. brizantha, comparada a $B$. pilosa, causou maior redução na altura, 
Tabela 2 - Valores para altura de plantas, número de folíolos, massa seca de caule (MSC) e massa seca da parte aérea (MSPA) de plantas de soja (variedade CD 219RR, resistente ao glyphosate), cultivadas em solo submetido a diferentes níveis de compactação na camada de 5-15 cm e em competição com as plantas daninhas Bidens pilosa e Brachiaria brizantha

\begin{tabular}{|c|c|c|c|c|c|c|c|c|c|}
\hline $\begin{array}{c}\text { Densidade } \\
\left(\mathrm{g} \mathrm{cm}^{3}\right)\end{array}$ & \multicolumn{3}{|c|}{ Altura $(\mathrm{cm})$} & \multicolumn{3}{c|}{ Número de folíolos } & \multicolumn{3}{c|}{ MSC $(\mathrm{g})$} \\
\cline { 2 - 10 } & $\mathrm{S}$ & $\mathrm{S}+\mathrm{P}$ & $\mathrm{S}+\mathrm{B}$ & $\mathrm{S}$ & $\mathrm{S}+\mathrm{P}$ & $\mathrm{S}+\mathrm{B}$ & $\mathrm{S}$ & $\mathrm{S}+\mathrm{P}$ & $\mathrm{S}+\mathrm{B}$ \\
\hline 1,00 & $26,7 \mathrm{a}$ & $26,7 \mathrm{a}$ & $26,0 \mathrm{a}$ & $39,2 \mathrm{a}$ & $36,5 \mathrm{a}$ & $22,0 \mathrm{~b}$ & $1,59 \mathrm{a}$ & $1,26 \mathrm{~b}$ & $1,06 \mathrm{~b}$ \\
\hline 1,20 & $30,0 \mathrm{a}$ & $25,2 \mathrm{~b}$ & $28,2 \mathrm{ab}$ & $32,5 \mathrm{a}$ & $29,7 \mathrm{a}$ & $19,0 \mathrm{~b}$ & $1,25 \mathrm{a}$ & $0,86 \mathrm{~b}$ & $1,05 \mathrm{ab}$ \\
\hline 1,40 & $31,2 \mathrm{ab}$ & $33,5 \mathrm{a}$ & $27,7 \mathrm{~b}$ & $31,0 \mathrm{a}$ & $24,0 \mathrm{ab}$ & $22,2 \mathrm{~b}$ & $1,18 \mathrm{a}$ & $1,16 \mathrm{a}$ & $1,05 \mathrm{a}$ \\
\hline 1,60 & $31,5 \mathrm{a}$ & $28,2 \mathrm{ab}$ & $24,8 \mathrm{~b}$ & $27,5 \mathrm{a}$ & $29,2 \mathrm{a}$ & $17,0 \mathrm{~b}$ & $1,05 \mathrm{~b}$ & $1,30 \mathrm{ab}$ & $1,37 \mathrm{a}$ \\
\hline $\mathrm{CV}(\%)$ & \multicolumn{4}{|c|}{9,57} & \multicolumn{4}{|c|}{14,68} & \multicolumn{4}{c}{12,56} \\
\hline
\end{tabular}

$\mathrm{S}=\operatorname{soja} ; \mathrm{S}+\mathrm{P}=$ soja em competição com picão (Bidens pilosa); $\mathrm{S}+\mathrm{B}=$ soja em competição com braquiária (Brachiaria brazantha). Médias seguidas por letras iguais, na linha, para cada característica, não diferem entre si pelo teste de Tukey a 5\% de probabilidade.

no número de folíolos e na massa seca de plantas de soja (Tabelas 2 e 3). Sob maior grau de compactação, a massa seca de caule das plantas de soja foi superior quando em competição com as plantas daninhas, porém sem contribuição para número ou massa seca de folíolos (Tabelas 2 e 3).

A área foliar das plantas de soja pode ser considerada a característica mais afetada (da parte aérea) pela competição com as plantas daninhas avaliadas, sendo tal efeito mais pronunciado com o aumento do grau de compactação no solo (Tabelas 2 e 3). Semelhantemente ao observado para as demais características, o potencial para expansão da área das folhas da cultura foi mais prejudicado em virtude da competição com a gramínea, em todos os graus de compactação do solo testados (Tabela 3). Esse efeito se refletiu na densidade das folhas, estimada por meio da área foliar específica (AFE), que relaciona área por unidade de massa seca (Tabela 3).

Já é bem relatada a melhor adaptação de gramineas a solos compactados. Além disso, por possuírem sistema enzimático mais eficiente na captura e na utilização de $\mathrm{CO}_{2}$, em ótimas condições de temperatura e luminosidade, espécies como $B$. brizantha são mais capacitadas para produção de massa seca. Essas afirmações são melhor constatadas quando se compara o efeito da competição da soja sobre as plantas daninhas. Para B. pilosa, as características mais afetadas, quando em competição com a cultura, foram a massa seca e a

Tabela 3 - Valores para massa seca de folhas (MSF), área foliar e área foliar específica (AFE) de plantas de soja (variedade CD 219RR, resistente ao glyphosate), cultivadas em solo submetido a diferentes níveis de compactação na camada de 5-15 cm e em competição com as plantas daninhas Bidens pilosa e Brachiaria brizantha

\begin{tabular}{|c|c|c|c|c|c|c|c|c|c|}
\hline \multirow{2}{*}{$\begin{array}{c}\text { Densidade } \\
\left(\mathrm{g} \mathrm{cm}^{3}\right)\end{array}$} & \multicolumn{3}{|c|}{ MSF $(\mathrm{g})$} & \multicolumn{3}{c|}{ Área foliar $\left(\mathrm{m}^{2}\right)$} & \multicolumn{3}{c|}{ AFE $\left(\mathrm{m}^{2} \mathrm{~g}^{-1}\right)$} \\
\cline { 2 - 10 } & $\mathrm{S}$ & $\mathrm{S}+\mathrm{P}$ & $\mathrm{S}+\mathrm{B}$ & $\mathrm{S}$ & $\mathrm{S}+\mathrm{P}$ & $\mathrm{S}+\mathrm{B}$ & $\mathrm{S}$ & $\mathrm{S}+\mathrm{P}$ & $\mathrm{S}+\mathrm{B}$ \\
\hline 1,00 & $1,97 \mathrm{a}$ & $1,95 \mathrm{a}$ & $1,71 \mathrm{a}$ & $0,034 \mathrm{a}$ & $0,028 \mathrm{~b}$ & $0,017 \mathrm{c}$ & $0,017 \mathrm{a}$ & $0,015 \mathrm{~b}$ & $0,010 \mathrm{c}$ \\
\hline 1,20 & $2,23 \mathrm{a}$ & $1,86 \mathrm{a}$ & $1,85 \mathrm{a}$ & $0,030 \mathrm{a}$ & $0,027 \mathrm{~b}$ & $0,016 \mathrm{c}$ & $0,017 \mathrm{a}$ & $0,015 \mathrm{a}$ & $0,009 \mathrm{~b}$ \\
\hline 1,40 & $2,42 \mathrm{a}$ & $2,38 \mathrm{a}$ & $2,29 \mathrm{a}$ & $0,027 \mathrm{a}$ & $0,021 \mathrm{~b}$ & $0,015 \mathrm{c}$ & $0,011 \mathrm{a}$ & $0,009 \mathrm{~b}$ & $0,007 \mathrm{~b}$ \\
\hline 1,60 & $2,39 \mathrm{a}$ & $1,93 \mathrm{~b}$ & $1,38 \mathrm{c}$ & $0,023 \mathrm{a}$ & $0,021 \mathrm{~b}$ & $0,015 \mathrm{c}$ & $0,012 \mathrm{a}$ & $0,009 \mathrm{~b}$ & $0,011 \mathrm{ab}$ \\
\hline $\mathrm{CV}(\%)$ & \multicolumn{4}{|c|}{10,89} & \multicolumn{4}{|c|}{3,47} & \multicolumn{4}{c|}{11,76} \\
\hline
\end{tabular}

$\mathrm{S}=$ soja; $\mathrm{S}+\mathrm{P}=$ soja em competição com picão (Bidens pilosa); $\mathrm{S}+\mathrm{B}=$ soja em competição com braquiária (Brachiaria brazantha). Médias seguidas por letras iguais, na linha, para cada característica, não diferem entre si pelo teste de Tukey a $5 \%$ de probabilidade. 
área das folhas, quando as densidades na camada compactada do solo eram de 1,4 e $1,6 \mathrm{~kg} \mathrm{dm}^{-3}$ (Tabela 4). Excetuando-se a massa seca da parte aérea e a área foliar no maior grau de compactação, a soja não promoveu efeito competitivo sobre $B$. brizantha (Tabela 5).

A produção de massa seca das raízes de soja foi menos de $50 \%$ quando em competição, comparada ao seu crescimento isolado, sendo sensivelmente diminuída com o aumento do grau de compactação do solo (Figura 1). Considerando-se somente a competição, houve pequena variação na produção de raízes da cultura, porém com decréscimos lineares - no caso da convivência com $B$. brizantha (Figura 1) - com o aumento na densidade do solo.

Apesar da maior agressividade na competição entre $B$. brizantha e soja para produção de área foliar, o aumento no grau de compactação do solo afetou mais negativamente essa característica quando a cultura se desenvolveu isoladamente ou em competição com B. pilosa, onde as curvas apresentaram maior inclinação (Figura 2).

Entre as plantas daninhas, B. pilosa foi mais afetada pelo aumento na compactação do solo quando em competição com a soja, apresentando decréscimo expressivo na produção de área foliar (Figura 3). Para B. brizantha, apesar de, nas menores densidades, os valores para área foliar terem sido maiores quando as plantas cresceram isoladamente, na competição, densidades no solo superiores a $1,34 \mathrm{~kg} \mathrm{dm}^{-3}$ (ponto de interceptação entre as regressões) promoveram maiores quedas quando em competição com a planta de soja (Figura 4).

Apesar das afirmações a respeito da provável superioridade de $B$. brizantha em relação a $B$. pilosa, em campo algumas situações podem favorecer a competitividade da segunda em relação à primeira. Observando-se a produção

Tabela 4 - Valores para altura de plantas, número de folíolos, massa seca de parte área (MSPA) e área foliar de plantas de Bidens pilosa (picão-preto), cultivadas em solo submetido a diferentes níveis de compactação na camada de 5-15 cm, isolada ou em competição com a soja (variedade CD 219RR, resistente ao glyphosate)

\begin{tabular}{|c|c|c|c|c|c|c|c|c|}
\hline \multirow{2}{*}{$\begin{array}{c}\text { Densidade } \\
\left(\mathrm{g} \mathrm{cm}^{3}\right)\end{array}$} & \multicolumn{2}{|c|}{ Altura $(\mathrm{cm})$} & \multicolumn{2}{c|}{ Número de folíolos } & \multicolumn{2}{c|}{ MSPA $(\mathrm{g})$} & \multicolumn{2}{c|}{ Área foliar $\left(\mathrm{cm}^{2}\right)$} \\
\cline { 2 - 9 } & Isolado & Com soja & Isolado & Com soja & Isolado & Com soja & Isolado & Com soja \\
\hline 1,00 & $27,50 \mathrm{a}$ & $24,25 \mathrm{a}$ & $66,75 \mathrm{~b}$ & $115,00 \mathrm{a}$ & $3,73 \mathrm{a}$ & $3,46 \mathrm{a}$ & $458,76 \mathrm{a}$ & $433,82 \mathrm{a}$ \\
\hline 1,20 & $28,00 \mathrm{a}$ & $22,38 \mathrm{a}$ & $116,50 \mathrm{a}$ & $114,00 \mathrm{a}$ & $3,81 \mathrm{a}$ & $3,52 \mathrm{a}$ & $504,51 \mathrm{a}$ & $508,74 \mathrm{a}$ \\
\hline 1,40 & $29,25 \mathrm{a}$ & $24,00 \mathrm{a}$ & $143,25 \mathrm{a}$ & $70,25 \mathrm{~b}$ & $4,05 \mathrm{a}$ & $1,62 \mathrm{~b}$ & $495,11 \mathrm{a}$ & $255,72 \mathrm{~b}$ \\
\hline 1,60 & $23,50 \mathrm{a}$ & $15,75 \mathrm{~b}$ & $89,00 \mathrm{a}$ & $50,00 \mathrm{~b}$ & $2,77 \mathrm{a}$ & $1,39 \mathrm{~b}$ & $429,85 \mathrm{a}$ & $131,04 \mathrm{~b}$ \\
\hline CV $(\%)$ & \multicolumn{3}{|c|}{11,63} & \multicolumn{3}{c}{15,72} & \multicolumn{3}{c|}{8,99} & \multicolumn{2}{c|}{10,24} \\
\hline
\end{tabular}

Médias seguidas por letras iguais na linha, para cada característica, não diferem entre si pelo teste $\mathrm{F}$ a $5 \%$ de probabilidade.

Tabela 5 - Valores para altura de plantas, número de folhas, massa seca de parte área (MSPA) e área foliar de plantas de Brachiaria brizantha (braquiária), cultivadas em solo submetido a diferentes níveis de compactação na camada de 5-15 cm, isolada ou em competição com a soja (variedade CD 219RR, resistente ao glyphosate)

\begin{tabular}{|c|c|c|c|c|c|c|c|c|}
\hline \multirow{2}{*}{$\begin{array}{c}\text { Densidade } \\
\left(\mathrm{g} \mathrm{cm}^{3}\right)\end{array}$} & \multicolumn{2}{|c|}{ Altura $(\mathrm{cm})$} & \multicolumn{2}{c|}{ Número de folhas } & \multicolumn{2}{c|}{ MSPA $(\mathrm{g})$} & \multicolumn{2}{c|}{ Área foliar $\left(\mathrm{cm}^{2}\right)$} \\
\cline { 2 - 10 } & Isolado & Com soja & Isolado & Com soja & Isolado & Com soja & Isolado & Com soja \\
\hline 1,00 & $81,50 \mathrm{a}$ & $73,00 \mathrm{a}$ & $20,50 \mathrm{a}$ & $18,50 \mathrm{a}$ & $5,69 \mathrm{a}$ & $4,72 \mathrm{a}$ & $165,34 \mathrm{a}$ & $190,20 \mathrm{a}$ \\
\hline 1,20 & $76,75 \mathrm{a}$ & $75,25 \mathrm{a}$ & $22,75 \mathrm{a}$ & $18,00 \mathrm{a}$ & $6,17 \mathrm{a}$ & $6,85 \mathrm{a}$ & $184,11 \mathrm{a}$ & $200,85 \mathrm{a}$ \\
\hline 1,40 & $76,00 \mathrm{a}$ & $73,25 \mathrm{a}$ & $22,25 \mathrm{a}$ & $19,75 \mathrm{a}$ & $6,11 \mathrm{a}$ & $6,19 \mathrm{a}$ & $173,46 \mathrm{a}$ & $162,8 \mathrm{a}$ \\
\hline 1,60 & $75,50 \mathrm{a}$ & $65,50 \mathrm{a}$ & $23,75 \mathrm{a}$ & $13,75 \mathrm{~b}$ & $5,78 \mathrm{a}$ & $3,52 \mathrm{~b}$ & $139,98 \mathrm{a}$ & $63,40 \mathrm{~b}$ \\
\hline & \multicolumn{4}{|c|}{8,75} & \multicolumn{2}{c|}{11,33} & \multicolumn{2}{c|}{9,42} \\
\hline
\end{tabular}

Médias seguidas por letras iguais na linha, para cada característica, não diferem entre si pelo teste $\mathrm{F}$ a $5 \%$ de probabilidade. 
total de raízes, a comparação - somente possibilitada nos tratamentos sem competição entre as espécies vegetais cultivadas mostrou diferenças na exploração radicular com o aumento do grau de compactação. Estabeleceuse a distribuição percentual de raízes entre os anéis para cada densidade de solo proposta. Apesar de ser resultado de estatística descritiva, pode-se perceber exploração diferenciada pela espécie $B$. pilosa. Como era esperado (em

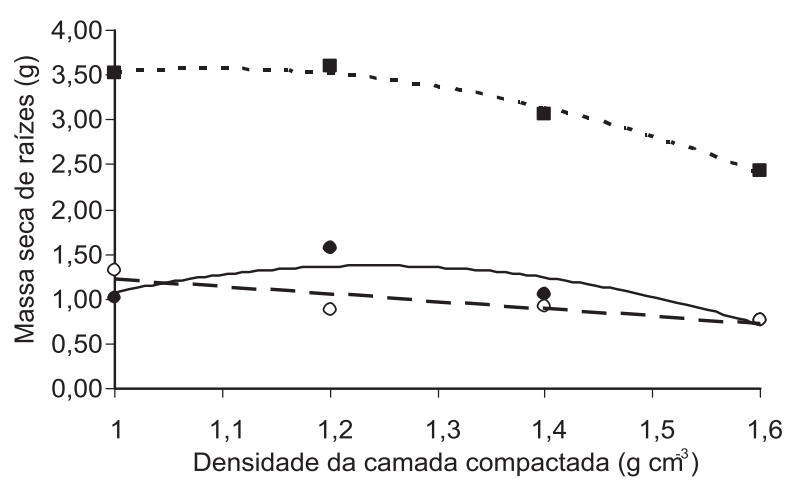

Figura 1 - Massa seca total de raízes das plantas de soja $\left(\longrightarrow \hat{\mathrm{y}}=-6,5383+12,758 D^{*}-5,1437 D^{2^{*}} ; R^{2}=0,74\right)$, Bidens pilosa $\left(--0 \hat{\mathrm{y}}=2,0425-0,821 D^{*} ; R^{2}=0,75\right)$ e Brachiaria brizantha (- - - $\mathbf{0}=-1,731+9,7474 D^{*}$ - 4,4766 $\left.D^{2} ; R^{2}=0,98\right)$, cultivadas em solo submetido a diferentes níveis de compactação na camada de $5-15 \mathrm{~cm}$. $\mathrm{D}=$ densidade do solo; ${ }^{*}=$ significativo pelo teste $t$ a $5 \%$ de probabilidade.

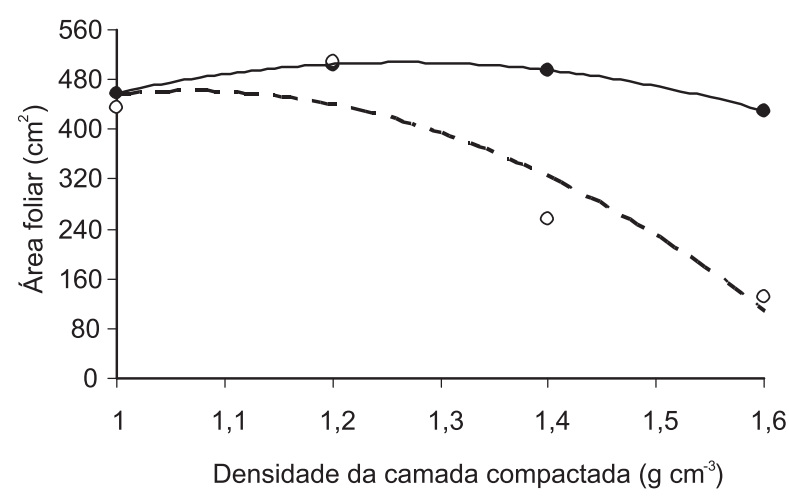

Figura 3 - Área foliar de Bidens pilosa aos 25 dias após emergência, desenvolvendo-se em solo submetido a diferentes níveis de compactação na camada de $5-15 \mathrm{~cm}$, isolada $\left(\longrightarrow \hat{\mathrm{y}}=-603,419+1756 D^{*}-693,887 D^{2 *} ; R^{2}=0,99\right)$ e em competição com a soja ( - - - o $\quad \hat{y}=-958,699+$ $\left.2662,88 D^{*}-1247,5 D^{2 *} ; R^{2}=0,88\right)$. $\mathrm{D}=$ densidade do solo; $*$ significativo pelo teste $t$ a $5 \%$ de probabilidade.

Planta Daninha, Viçosa-MG, v. 26, n. 1, p. 123-130, 2008 função do menor volume), menor quantidade de raízes foi observada no anel superior. Todavia, acompanhando a distribuição entre os anéis, com o aumento da densidade, percebese que $B$. pilosa possui maior eficiência de penetração da camada compactada, apresentando maior crescimento relativo no anel inferior (Figura 5). Esse fato demonstra que essa espécie pode apresentar elevada capacidade competitiva se, durante o cultivo da soja,

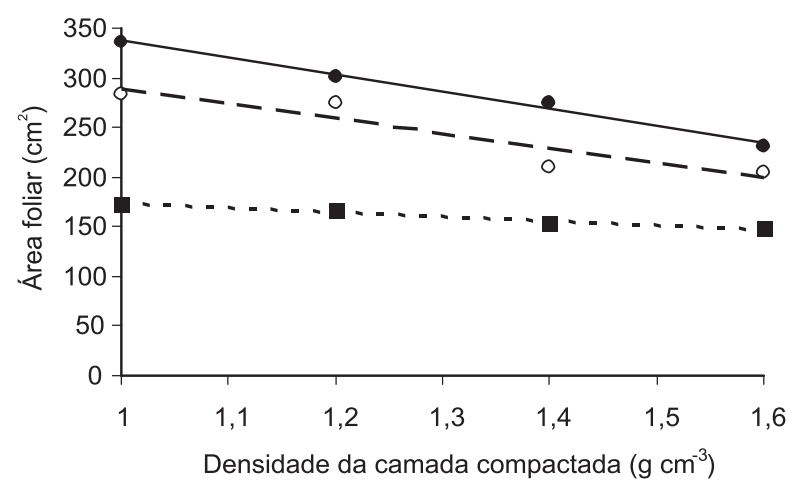

Figura 2 - Área foliar da soja aos 25 dias após emergência, desenvolvendo-se em solo submetido a diferentes níveis de compactação na camada de $5-15 \mathrm{~cm}$, isoladamente (— $\left.\hat{y}=507,233-170,33 D^{*} ; R^{2}=0,99\right)$ e em comparação com as espécies Bidens pilosa (- - - $\hat{\mathrm{y}}=437,756-149,38 D^{*}$; $\left.R^{2}=0,89\right)$ ou Brachiaria brizantha (- - - $\hat{y}=217,721$ $\left.43,681 D^{*} ; R^{2}=0,96\right) . \mathrm{D}=$ densidade do solo; $*$ significativo pelo teste $t$ a $5 \%$ de probabilidade.

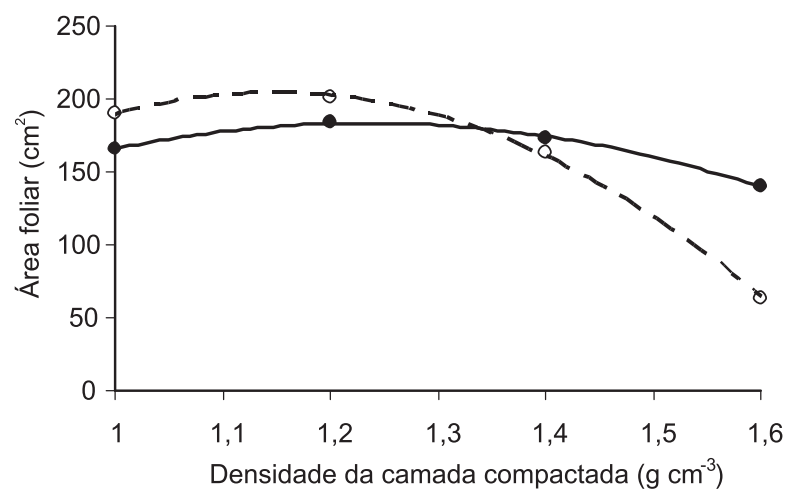

Figura 4 - Área foliar de Brachiaria brizantha aos 25 dias após emergência, desenvolvendo-se em solo submetido a diferentes níveis de compactação na camada de $5-15 \mathrm{~cm}$, isolada (— $\hat{\mathrm{y}}=-313,376+805,544 D^{*}-326,552 D^{2 *}$; $\left.R^{2}=0,99\right)$ e em competição com a soja ( - - o $\left.\hat{\mathrm{y}}=-701,822+1579,33 D^{*}-687,87 D^{2^{*}} ; R^{2}=0,99\right)$. $\mathrm{D}=$ densidade do solo; ${ }^{*}=$ significativo pelo teste $t$ a $5 \%$ de probabilidade. 


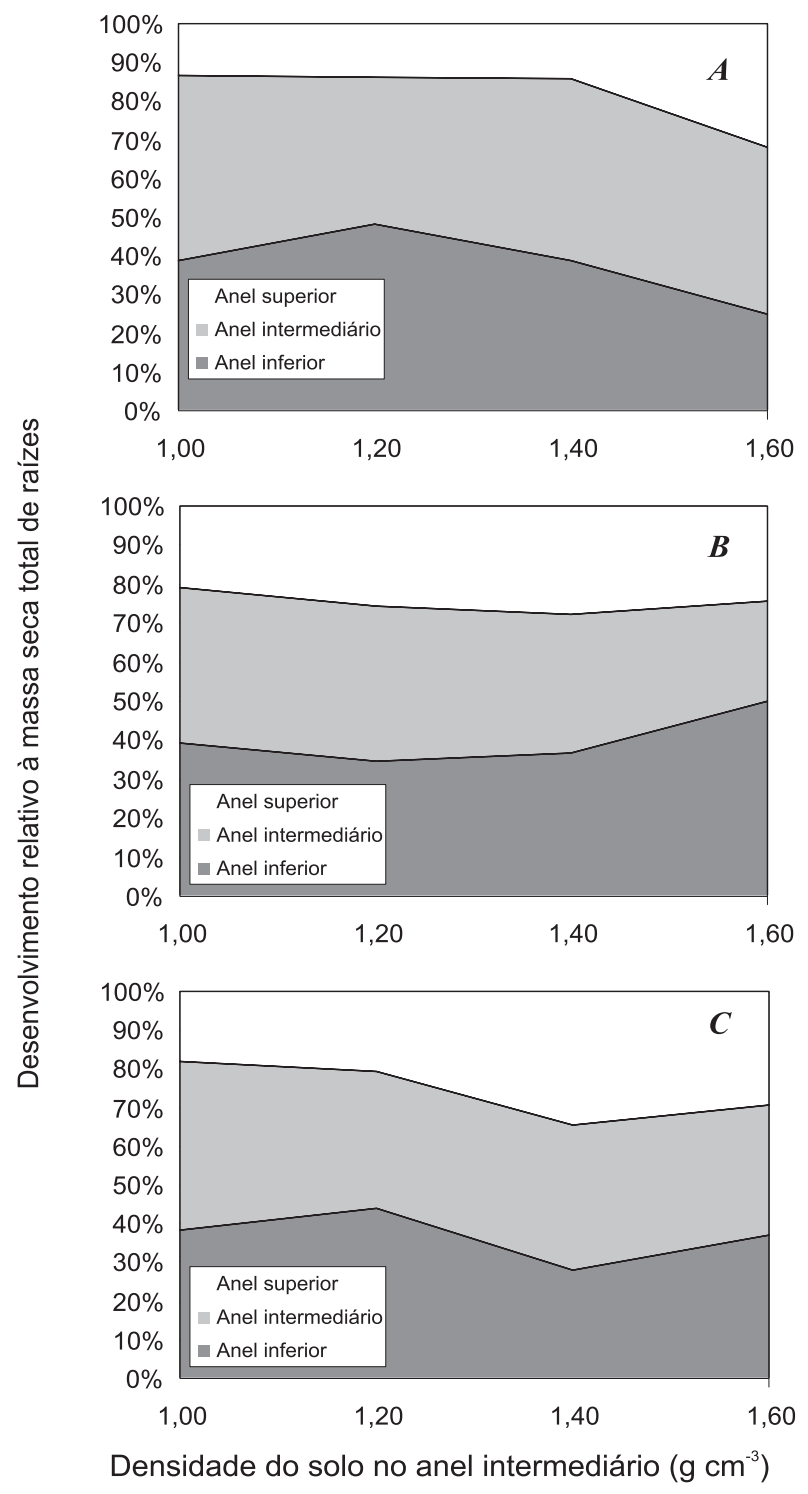

Figura 5 - Distribuição percentual de raízes das espécies vegetais soja (Glycine max - A), picão-preto (Bidens pilosa - B) e braquiária (Brachiaria brizantha - C) em colunas de solo divididas em três camadas (anel superior, com $5 \mathrm{~cm}$ e densidade de 1,2 $\mathrm{g} \mathrm{cm}^{-3}$; anel intermediário, com $10 \mathrm{~cm} \mathrm{e}$ densidade variando de 1,0 a 1,6 $\mathrm{g} \mathrm{cm}^{-3}$; e anel inferior, com $10 \mathrm{~cm}$ e densidade $1,2 \mathrm{~g} \mathrm{~cm}^{-3}$ ).

fatores como fornecimento de água ou de nutrientes de baixa mobilidade no solo forem limitantes.

Em áreas com recente adoção do sistema de plantio direto, a compactação superficial, observada em conseqüência da falta de revolvimento do solo, poderá favorecer plantas de B. pilosa. Vários estudos constataram o aumento na densidade em profundidades inferio- res a $20 \mathrm{~cm}$ (Daniel \& Maretti, 1990; Secco et al., 2004). Considerando os resultados obtidos por Procópio et al. (2004), os quais estabeleceram que plantas de $B$. pilosa são capazes de sobreviver em ambientes onde a retenção de água no solo é três vezes mais negativa do que aquela que causaria a murcha permanente de outras plantas, inclusive a soja, percebese porque essa espécie tem sido relatada entre as mais agressivas nas principais culturas do Brasil (Ronchi \& Silva, 2006; Vidal et al., 2006).

Considerando-se o maior percentual de raízes da soja na camada superior das colunas, em resposta à dificuldade em romper a camada compactada nas maiores densidades (Figura 5), podem-se perceber as causas do efeito negativo observado na parte aérea das plantas.

Admitindo-se fornecimento adequado de nutrientes, principalmente fósforo, e de água durante o ciclo, a soja apresenta-se como forte competidora. A falta de manejo adequado para essas características favorece o desenvolvimento de espécies mais bem adaptadas a condições adversas, como grande parte das plantas daninhas. Nesse sentido, Brachiaria brizantha, independentemente do grau de compactação no solo, possui elevada interferência sobre o desenvolvimento da soja. Bidens pilosa é uma espécie com grande potencial para infestação devido à maior exploração do solo, mesmo em camadas compactadas, sendo seu efeito competitivo mais pronunciado com o aumento da densidade do solo.

\section{LITERATURA CITADA}

DANIEL, L. A.; MARETTI, H. J. Avaliação de camada de solo compactada e análise de crescimento de plantas. In: SILVEIRA, G. M. (Coord.) CICLO DE ESTUDOS SOBRE MECANIZAÇÃO AGRÍCOLA, 4., 1990, Jundiaí. Anais... Campinas: Fundação Cargill, 1990. p. 22-33.

FERREIRA, E. A. et al. Glyphosate no controle de biótipos de azevém e impacto na microbiota do solo. Planta

Daninha, v. 24, n. 3, p. 573-578, 2006.

FOLONI, J. S. S. Efeito da compactação do solo no desenvolvimento aéreo e radicular de cultivares de milho. Pesq. Agropec. Bras., v. 38, n. 8, p. 947-953, 2003.

GUIMARÃES, C. M. et al. Compactação do solo na cultura do feijoeiro II. Efeito sobre o desenvolvimento radicular e da parte aérea. R. Bras. Eng. Agríc. Amb., v. 6, n. 2, p. 213218, 2002. 
HAKANSSON, I.; VOORHEES, W. B. Soil compaction. In: LAL, R. et al. (Eds.) Methods for assessment of soil degradation. Boca Raton: Lewis Publishers, 1996. p. 167179 .

MATERECHERA, S. A. et al. Influence of root diameter on the penetration of seminal roots into a compacted subsoil. Plant Soil, v. 144, p. 297-303, 1992.

MONQUERO, P. A. Plantas transgênicas resistentes aos herbicidas: situação e perspectivas. Bragantia, v. 64, n. 4, p. $517-531,2005$.

PROCÓPIO, S. O. et al. Ponto de murcha permanente de soja, feijão e plantas daninhas. Planta Daninha, v. 22, n. 1, p. 35-41, 2004.

RONCHI, C. P.; SILVA, A. A. Effects of weed species competition on the growth of young coffee plants. Planta Daninha, v. 24, n. 2, p. 451-423, 2006.

RUSSEL, R. S.; GOSS, M. J. Physical aspects of soil fertility: The response of roots to the mechanical impedance Nether. J. Agric. Sci., v. 22, p. 305-318, 1974

SECCO, D. et al. Produtividade de soja e propriedades físicas de um Latossolo submetido a sistemas de manejo e compactação. R. Bras. Ci. Solo, v. 28, n. 5, p. 797-804, 2004.
SILVA, A. A. et al. Biologia de plantas daninhas. In: SILVA, A. A.; SILVA, J. F. (Eds.) Tópicos em manejo de plantas daninhas. Viçosa, MG: Universidade Federal de Viçosa, 2007. p. $17-62$.

SOANE, B. D.; van OUWERKERK, C. Soil compaction problems in world agriculture. In: SOANE, B.D. \& van OUWERKERK, C. (Eds.) Soil compaction in crop production. Amsterdam: Elsevier, 1994. p. 1-21.

TIMOSSI, P. C.; DURIGAN, J. C.; LEITE, G. J. Eficácia de glyphosate em plantas de cobertura. Planta Daninha, v. 24, n. 3 , p. $475-480,2006$.

TORMENA, C. A.; ROLOFF, G. Dinâmica da resistência à penetração de um solo sob plantio direto. R. Bras. Ci. Solo, v. 20, p. 333-339, 1996.

VARGAS, L. et al. Alteração das características biológicas dos biótipos de azevém (Lolium multiflorum) ocasionada pela resistência ao herbicida glyphosate. Planta Daninha, v. 23, n. 1, p. $153-160,2005$.

VIDAL, R. A. et al. Relação entre distância geográfica e variabilidade genética de uma população de Bidens spp. com resistência aos herbicidas inibidores de ALS. Planta

Daninha, v. 24, n. 1, p. 149-155, 2006.

WINKLER, L. M.; VIDAL, R. A.; BARBOSA NETO, J. F. Aspectos genéticos envolvidos na resistência de plantas daninhas aos herbicidas. R. Plantio Direto, v. 70, n. 4, p. 21-24, 2002. 